\title{
State of environmental awareness in northeastern Montenegro: a review
}

\author{
Goran Rajović ${ }^{1, a}$, Jelisavka Bulatović ${ }^{2, b}$ \\ ${ }^{1}$ Street Vojvode Stepe 252, Belgrade, Serbia \\ Phone: 0038161/19-24-850 \\ ${ }^{2}$ Department of Textile Design, College of Technology and Management, \\ Street Starine Novaka 24, Belgrade, Serbia \\ Phone: 003861/ 3082651 \\ a,bE-mail address: dkgoran.rajovic@gmail.com, jelisavka.bulatovic@gmail.com
}

\begin{abstract}
Public participation so far is not dedicated adequate attention in areas environmental protection. The objective of this work is to consider environmental awareness in northeastern Montenegro, on the example of municipalities Berane, Petnjica, Andrijevica, Plav and Gusinje. In accordance with the concept of sustainable development it is necessary is directed population on raising awareness on environmental protection. When the public better acquainted with the environmental problems, will be are able to help in solving them.
\end{abstract}

Keywords: Northeastern Montenegro; population; environmental awareness; survey

\section{INTRODUCTION}

Protection of the environment today should be in the first place, because the development of industry and technology has reached the upper limit when they can no longer uncontrollably take raw materials from nature, and when more of nature cannot be discharged and disposed of waste materials without prior inspection and of purification [1-2]. We do not live in a time of prosperity industrialism, but the general crisis which the world is transformed, which slowly obeys all populations. Major changes that occur not threaten, but penetrate deep into our lives and completely transformed all around us, looking at all the wildlife. Every day around the world people are dying of various diseases, a cause can be found in a polluted environment (whether stored radioactive or chemical waste, which adversely affects the human organism) [3].

Global danger to nature and society arising from the state of the overall assumptions of man's relationship to the environment, or large and unforgivable mistakes that one makes in the process of work based on the enormous technical and technological development, not prevent the consequences that impair a person's environment and harmonious relationship between nature and society. Means "man caught big aspirations in terms of the level of life, uncontrolled use of the possibilities of technological revolution" [4]. 
Our research evidence based on similar research Pušić and Pajvančić- Cizelj [5] emphasizes that the environmental awareness of the citizens of northeastern Montenegro formed a "part of the media and institutional schematization of environmental problems through their directly observable consequences (pollution).The fact that the respondents caused environmental problems in most seen in the legal legislation interpreted in the context of transition where it forms a pattern of "sufferance" and passively waiting shelf solutions "from above". In the study been confirmed the existence of environmental values among the respondents, but it turned out that they were permanent and that the consequences of conformity and giving socially desirable answers. This situation can be characterized as the (only) the first step on the road to building an environmentally sustainable society. The next steps would certainly have to include deeper problems of social causes and social consequences of environmental problems. That would contribute to the scientific conception of the social acceptance of the concept of the unity of the natural environment and social aspects of human life. The perception of the environment as a social category requires an understanding of their role in shaping the environment and, consequently, the formation grass scoots initiatives grounded in ecological culture as a way of life".

Ecological problems are becoming one of the most current topics, and therefore information in this field is of great importance. In this regard, it is important to point out that the importance of environmental culture is reflected not only in order to orientation behavior in the local community in which the individual moves on a daily basis, but also to the general action in the direction of environmental protection at the global level [6-7]. On the basis of the aforementioned, we can conclude that social factors are an important factor in shaping and guiding environmentally desirable behavior that future research should detail to illuminate [8$10]$.

\section{RESEARCH METHODOLOGY}

Poll is a special method of collecting data by which we obtain information about the attitudes and opinions of respondents. According to Pinsonneault and Kraemer [11], Vallée et al [12], Evans and Mathur [13], the importance of polls is not in asking questions and finding answers two of them, already the essence of the polls ask strictly defined questions, exactly particular group and the number of people in a certain way. Kelleey et al [14], Tourangeau [15], Jansen et al [16], point out that poll determine the problem, who research we solve. According to Jansen [16], when filling out the questionnaire, it is important the poll is that it contains an introduction and an explanation of what we want to achieve poll and why would the respondents supposed make an effort to give honest answers. Starr [17], Fricker and Schonlau [18], Ramos i Goihman [19], Collier [20], Duque et al [21], the correct order of the questions in the poll decisive influence of quality of responses, and that we ensure quality execution of the survey, it is important to: language of the survey is understandable that answers are short and refined, that matters not use emotionally colored words that can influence the direction of the response, as well as the questionnaire does not contain leading questions that can focus on a specific answer.

The survey population of northeastern Montenegro was conducted in two occasions in late July 2012 and mid-August 2013. Survey questionnaire included the total of 26 questions divided in two comparable entities: attitudes about environmental protection (environmental attitudes) and behavior directed to protection of the environment (ecological behavior). The sample was comprised of 127 respondents from five municipalities in north-eastern 
Montenegro (Berane, Petnjica, Andrijevica, Plav and Gusinje). The demographic structure of the sample is present in slightly higher number of women $(53.5 \%)$ compared to men $(46.5 \%)$.

The largest number of respondents was aged 18-31 years $(32.3 \%)$, followed by $32-45$ $(30.7 \%)$, while the lowest number of respondents was in the age group over 60 years $(12.6 \%)$. The largest part of the sample consisted of respondents who were employed $(59.3 \%)$, followed by unemployed (29.8\%), and least of pensioners $(10.9 \%)$. By level of education most of the sample consisted of respondents with secondary education $(66.9 \%)$, followed by those with primary education (26.3\%), incomplete primary education $(6.5 \%)$ and the least of the respondents were college and faculty $(0.3 \%)$. This pattern is constructed to give the opinion the working age population who is the holder of economic activity and supported contingents of the population.

\section{ANALYSIS AND DISCUSSION}

Environmental awareness is part of a broader philosophy of social movement directed at preserving and improving the natural environment, both in the interest of the individual and in the interest of civilization and its survival as a whole [22]. Man's awareness of the negative effects of their practical relation to nature has gradually grown into environmental awareness through the process of self-awareness of his awareness about their own vulnerability and the danger of self-destruction, as a result of his possessed exploitation and pollution of natural environment [23].

Turbulent life of modern society, unpredictable future, the particularity of knowledge concerning the fundamental questions of existence, the awareness that the ecological crisis has global dimensions show that traditional models of behavior. The registration aspects of today's ecological crisis such as: loss of activity in the area, loss of competence forecasting, loss of visibility and irreversible environmental damage causes formation of new social paradigm in the field of behavior, which should become a strong, integral part of human beliefs, deriving from the perception of a new relationship of man to nature [24].

Our research evidence based on similar researches Stamenković and Stamenković [25], Pušić and Pajvančić-Cizelj [5], points out that the procedure of implementation of the survey is very positive, because we found a good response from people who have a lot of confidence and a desire for open cooperation accept the necessary suggestions regarding the filling of the questionnaire. This of course talking about is their previous, quite properly built environmental awareness. Personal information of residents surveyed about the concept of ecology is high, which indicates the current subconscious readiness and familiarity with current environmental events in northeastern Montenegro and wider. Specifically, respondents detect the analyzed territory of a significant number of contaminants that disrupt the prescribed rules of modern environmental standard. This primarily refers to the large number of "illegal landfills" that adversely affect the preservation of a healthy environment. As the largest green ecological point of reference to the great city dump at the site Vasove water, away from the urban center of Berane only two kilometer. Then, something that significantly disrupts the natural environment is a large mining gravel from the riverbed Lima by the concessionaire, which is the river shifted from side to side, which greatly endangers the fish stocks. Respondents indicate unmistakably the enormous ecological problems "dumps in Gusinje" to "urban sewage system ...". The positive is the fact that there is a general environmental awareness of the respondents about the need for designing various environmental programs. However, it also reveals the fact that surveyed residents do not have 
a clear picture of how and in what way the ecological problem solved. With the right emphasize the many authors; among them this time apostrophized Tarrant and Cordell [26], Akinola et al [27], Sarker et al [28] that although environmental problems belong to the group you need to deal with local and state authorities should not ignore the role the individual has in the entire system. Individual consciousness, an awareness of the real dangers and threats to both himself and all other living beings and their behavior are a key factor in changing the overall environmental picture and this part of northeastern Montenegro. According to Franzen [29], Huang et al [30], Liu et al [31], so that we can take steps to changing environmental consciousness and behavior of the citizens first would be important to determine to what extent they have been informed about the causes and consequences of environmental problems, how they perceive the problems, and how to treat them in real life situations. For this purpose, a survey was conducted with the primary objective was to determine the level of development of environmental awareness, environmental awareness, and self-assessment proenvironmental behavior.

Abiding by the rules of the survey wording of the question LEAP - Local environmental action plan Bor [32], and adapting the text of this research, and will use the research Rajović and Bulatović [33], Bulatović and Rajović [34], Bulatović and Rajović [35-37], and below is an overview of the analysis results.

1. Based on the of data analysis we determined that $94,72 \%$ of respondents considers himself a nature lover, while only $5,28 \%$ of respondents believe that it is not.

2. Is interesting that the almost all respondents, more precisely $96,21 \%$ pleaded to behave in an environmentally responsibly and only $3,79 \%$ of respondents said they did not.

3. Even $66,37 \%$ of respondents believe that something does for the benefit of the environment, 33,63\% stated other reasons (that is the job of local self, government, the various environmental organizations ...). As an example, rendered the welfare of the environment respondents cited "Assembly of citizens of the local community Vusanje" for fear that the construction of hydroelectric power was threatened by a major tourist destination Plav, it is there to dry out rivers Grlje, waterfalls Grlja and Source Oko Skakavice. Implementation of the project would close the $16 \mathrm{~km}$ "source" for irrigation, which supplies about 2,000 acres of farmland, orchards and meadows, of particular importance for the life of the villagers Vusanje. Such a technical solution is not addressed in the "Draft detailed spatial plan" and "Strategic Environmental Assessment.

4. In the settlement launches or participate in the Environmental Protection 24,73\% of respondents. One such action March 2014 bore fruit and amounted to the regulation of "Excursion sites Jasikovac" would in mainly the youngest, as well as other neighbors, have made the environment more comfortable and safer. Total 22,97 \% of the respondents answered that does not participate in actions to protect the environment, while $52,30 \%$ of respondents not contemplating at all about it.

5. What programs are needed most young people was the question by which one wishes assess the opinion of respondents on the needs of the young generation. Education for a healthy life is a priority in the opinion of the respondents and it them $61,84 \%$. Total $16,32 \%$ respondents in another place highlights the need for programs of mass sports, the programs stay in nature opted to $11,56 \%$ of the respondents, while for the programs of voluntary action on the arrangement of the municipality declared them $5,13 \%$. Then, according to the survey respondents the following voluntary work 
activities with $2,79 \%$ of respondents for the "something else" is declared 2,36 \% of the respondents.

6. Survey showed that $79.57 \%$ of respondents believe that the solution too many environmental problems require new "Development Strategy", 16.11\% undecided, and only $4.32 \%$ is not required. With the right to Knežević [38] points out that "it is necessary to properly ecological education of the population, punish illegal construction, to prevent uncontrolled deforestation and pollution and degradation basic elements of the eco-system. Hence, there must be allow the national park Prokletije experience the fate of the eponymous regional park, measuring 12,000 hectares, which is the municipality Plav, declared in 2003. The strict protection zone of the park include sites: Plavsko Lake, Valley Vruje and Ropojane with Gusinjskim (Alipašinim) sources, Savin eye (Skakavičkim hot) and Grlje canyon with waterfalls, then Grbaje valley and surrounding mountains, Ridsko and Visitor lake with forest in reserves White Bark Pine environment. However, illegal and uncontrolled construction has already undermined the authenticity of the natural environment of almost all of these sites, especially Grbaje and Plavsko Lake. In Grbaji, which is envisaged as a center of the National Park, illegally erected houses and apartment buildings. A particular problem in this municipality is the excessive and uncontrolled deforestation, which has taken on elements of the real environmental disaster. Therefore, they are much heightened erosion processes. Vulnerable to the forest reserves White Bark Pine about Ridsko and Visitorskog Lake. In the municipality of Plav wood processing capacities are much higher than the allowable annual cut of timber felling. Apart from the privatized wood industrial company "Bor", there were over 30 registered and unregistered private power saws, sawmill and carpentry shop. With the exception of carpentry workshop, all Opal capacities are engaged in primary processing of wood, which requires a great need in the raw materials, i.e. the logs and of round wood".

7. Environmental awareness of individual population is reflected in the disposal of waste. A the implementation of polls we found out that even $89,25 \%$ respondents not dispose of waste "Natural resources" or in its immediate vicinity. However, 10,75\% of respondents the identified themselves the existence uncontrolled landfills the waste. Our research evidence based on similar studies Pjević [39] emphasizes that "came are some a sad time. Unconscientiously people have started to cut out forest and distracting trees for firewood. Some others are ... dumped piles of rubble in the forest, because it was the easiest thing...! Forest ... as if to anyone is not important ". Separate collection of different types of waste (glass, paper, plastic, cans ...) are not present in sufficient numbers so that people are forced to dispose of waste without sorting the basket, said $98,74 \%$ of respondents.

8. Characteristic is very critical opinion of respondents on the state of preserved natural values. Overwhelming majority believes that these areas protect only partially $(42.7 \%)$ or that generally do not protect $(57.3 \%)$.

9. Surveyed residents and to them 78,26\% believe that they can best protect Natural Resources (PLEASE FIND ATTACHED) development of environmental awareness, $19.83 \%$ the identified themselves for environmental education, and $1,91 \%$ claim that the solution to environmental action organization.

10. A disturbing fact is that $64,92 \%$ of respondents answered that nothing would not have taken when seen that someone throws trash out of baskets for garbage or container in the settlement of them $32,33 \%$ would cautioned by him, while the $2,75 \%$ of 
respondents would reported him to the competent authorities for the protection of the environment.

11. Opinion of respondents is that matters concerning environmental protection most deal with nongovernmental organizations and alleged by them $38,95 \%$. In second place respondents ranked the state institutions $(25,83 \%)$, the third municipal institutions $(22,74 \%)$, and then, as a little significant, following public companies $(4.75 \%)$, professional associations (4,08\%), schools $(3,74 \%)$, union organizations $(0,21 \%)$, while in the last place "some other "(for example, political parties ...) $0.70 \%$.

12. Television $(62,97 \%)$, it became absolutely evident, the most powerful medium through which is informs population about these important issues. In second place is the press $(8,65 \%)$, followed by radio $(8,02 \%)$. The school and the workplace as a source of information can be found in the last place $(7,84 \%)$. Even the impact of information which can be heard from the other "The story is ..." greater $(12,52 \%)$.

13. More than half of the respondents $(58,47 \%)$ are not satisfied gaining information about of the environment, $38,15 \%$ were partially satisfied and only $3,38 \%$ were completely satisfied.

14. Respondents have estimated the need for greater participation of citizens in decisionmaking on environmental protection. $76,22 \%$ is identified themselves that greater participation required $20,71 \%$ are indeterminate, and 3,07\% think that such a need does not exist.

15. During the research estimated are good and bad sides of involving the public in decision-making about the environment. They bring are better decisions considered $48,36 \%$ of the respondents, strengthens the trust of citizens claim $28,29 \%$, for the compromise of uses are declared $16,68 \%$ of respondents. Then the respondents reported that is increasing the level of expertise $-3,18 \%$ for active implementation of the decision are declared $2,58 \%$ of the respondents and in last place respondents stated $-0.91 \%$ there is no good side of public involvement in decision-making about the environment.

16. Asked whether would voluntarily work to help community to cope with environmental problems 38,64\% of respondents answered yes, $20,18 \%$ were not willing to engage in such activities while $41,18 \%$ are undecided. These attitudes suggest that citizens believe that environmental problems need to solve by someone else. I still not enough understood the importance and the manner of their personal involvement.

17. Out of 127 of respondents $56,92 \%$ of them have expressed willingness to provide assistance in the organization of cleaning and decoration of space, 24,31\% were willing to talk is other people about how to resolve environmental protection and to animate them for personal involvement, 9,88\% think that it can prepare the various information on how individuals can help, $4,95 \%$ of respondents it would be willing to make phone calls, a 2,04\% thinks he can help the community by writing articles in local newspapers about problems of environment. For "something else" is declared $1,90 \%$ of the respondents.

18. Disturbing fact is that $52,94 \%$ of respondents answered that the local government was not doing enough for the cleanliness the settlement or the park, and only 48,06\% of respondents, believes that it makes. Respondents believe that the government should hire more workers who need to care about the cleanliness of the village, and of course the guards whose task would be to ensure the protection of "natural resources".

19. To the question what would local governments do, respondents consider that local governments should bring relevant laws on environmental protection $(73,55 \%)$, 
financially helps $(18,41 \%)$ suggests the important projects in the field of ecology $(8,04 \%)$. Respondents stated that the existing "Law on the Protection of Nature" is the punishment prescribed for an individual to harass, abuse and fauna destroyed or destroying its habitat and destroys, breaks or otherwise wasteland of wild flora and destroys and destroys its habitat. For this behavior is the Law stipulated fines. However, it is not applied in practice.

20. Answer in the survey shows that $72,94 \%$ of respondents believe that urban pollution is already affecting their health, $12,61 \%$ think it is not, and $14,45 \%$ responded with perhaps. The quality of the natural environment in the northeastern part of Montenegro's most disturbed with the development of industry after World War I to the pollution of air and water flows. Today, a large part of the industrial plant is not in operation. However, the natural environment is disrupted and the devastation of the landscape, the construction of buildings on agricultural land and polluting waste. For the disposal of solid waste in industrial zones, there were only a temporary storage that are predominantly located in the vicinity of the river Lim which contributed to the ecological devastation of Lima, because urban settlements in the observed geo-space Berane have efficient utility system for the collection, transportation and recycling of solid waste. Also, there is no system for the treatment of industrial and municipal water and all sewerage and storm sewer urban areas flows into the water Lima, changing its physical - chemical characteristics, degrading water quality. This has reduced sports - recreational importance Lima, which is extremely suitable for a variety of sports as well as fishing [40].

21. The survey showed technological - technical aspects of the respondents identified as the most significant cause of environmental pollution. In the first place because they are old and outdated Technology The technological equipment $(42.74 \%)$ that is technical and technological aspects belong to the group of important priorities. Human factors it is improper management of the technological process is second which is $34.08 \%$ of the respondents identified themselves, third in the irregularity of technological equipment $(11.51 \%)$, while, on the fourth respondents ranked low environmental education and environmental awareness $(9.18 \%)$. The next group of factors, which are also recognized as important causes little pollution are factors related to legislation and enforcement. That was the fifth ranked non-compliance and inadequate inspections $(1.42 \%)$, sixth in the absence of appropriate regulations on environmental protection (0.71) and the seventh no consistency in penal policy towards Pollutants $(0.35)$ belongs to the very few important.

22. One of basic goals the survey also related to determining public opinion about what are the most important environmental problem in their neighborhood? In the first five most significant problems $52,76 \%$ of respondents admitted air pollution as a very important problem. Second place is water pollution $(20,31 \%)$, on the third soil pollution $(12,47 \%)$, on fourth human health $8,58 \%$, in fifth place respondent and to $3,05 \%$ of them alleges contamination of food, in sixth destruction of flora and animal life and to them 2,98 \% and in the last place respondents cited "other," and to them $0,85 \%$.

23. Of those surveyed population is asked their opinion about the ecological events. Are ecologically gatherings are good, but you should take concrete measures thought $45,27 \%$ of respondents, that are useful argues $27,18 \%$. Are ecologically gatherings a waste of time because they do not give a no results considers $8,93 \%$ of the 
respondents, for the environmental rallies in the settlement was heard even $15,69 \%$ of the respondents, and for gatherings not interested in attending them 2,93\%.

24. According to the survey $56,47 \%$ of respondents, weekly / monthly spend time in nature, $20.37 \%$ of them to makes the every day, and $23,16 \%$ of respondents, not think about that. Many studies Pretty et al [41], England [42], Akers et al [43], emphasize that people are often spend in nature much less susceptible to physical diseases. In other words, spending time in nature should become the priority for to people on the list of wishes, because it contributes to better physical and mental health.

25. On the question of whether the development of the region is possible without further development of mining and industry. Respondents offered answers on the use of renewable natural resources. Specifically, respondents believe that agriculture is an industry that has great prospects for her declared $48.63 \%$. In second place is tourism (40.76), while the forestry and wood processing in third place (10.61\%).

26. The survey of residents has been asked their opinion on the conservation of cultural heritage. Respondents considered and $54.83 \%$ of them it is necessary to take care of the village, the art colony chose to $12.45 \%$ of the respondents, for organizing the festival $10.07 \%$, for new organizations in culture $9,15 \%$, for the renovation of buildings $6.52 \%, 4.38 \%$ for libraries and anything else $1.97 \%$. Cultural heritage is a unique and irreplaceable cultural value because it created generations, directly points to the overall social and educational, and cultural and civilization level of development. The value of cultural heritage, whether it is a tangible or intangible, is constantly increasing due to the natural conditional duration, but the unstable environment in the development of new technologies and changes in style and lifestyle. Therefore, the concern about the preservation of cultural heritage in the XXI century, not only declarative obligations of relevant institutions but to the moral role of the modern society, recognizing the importance of cultural heritage, creates the conditions for its preservation in the future" [44].

\section{CONCLUSIONS}

On the basis of data obtained from the questionnaire, it appears a few concluding statements, based on similar studies [45]:

1. The largest number of respondents aware that this was the man cause pollution of the environment, but do not recognize him as an actor who is responsible for such action,

2. There is no system of informal education in the field of environmental protection even though education at all levels stand out as an important tool in improving this area and that it should be the protection of the environment introduced as a compulsory subject in school curricula and strengthen cooperation with schools,

3. Does not indicate a positive case studies of improving environmental protection,

4. Awareness in the field of the environment is not satisfactory, there is no adequate channels of communication, there is no transparency in the information and that the low level of youth activism,

5. Organization of environmental of voluntary work camps positive example,

6. Urgently address the issue water pollution and problems of wild and urban landfills (Vasove Water, Sućeska, Grnčar), 
7. Need to strengthen cooperation between the competent authorities in municipalities and youth offices, primarily in the search for solutions to the strategic involvement of youth in addressing environmental issues and resolving conflicts. As an example, mention three-day camp on Plavsko Lake 2014. Young people in workshops and specialized training modules taught how to recognize their own capacity, improved skills for making short-term and long-term plans, as well as to define their own goals,

8. There are not enough skilled personnel and the necessary professional and competent people in important positions,

9. Youth as a major problem in their cities highlight those related to large infrastructure projects,

10. Education for environmental protection should start in preschool, and schools should be based more on peer education,

11. Should enhance the motivation of young people recognizing hard work by introducing awards,

12. Should improve the transparency of the institutions and enhance the cooperation of all stakeholders (professional institutions, local governments, civil society, individuals ...) and to overcome the bad organization of all sizes,

13. It is necessary to organize a campaign in which they will spread awareness that animals are part of the environment, but also raise the general culture and behavior towards the environment and education on environmental rights and obligations. As positive examples, ecological society "Popče" from Petnjica. Ecological Society "Popče" brings together true nature lovers. Initiators are several projects whose ultimate goal is to beauty cicadas newly established municipalities Petnjica as close to visitors - ideal for the development of mountain, rural and eco-tourism.

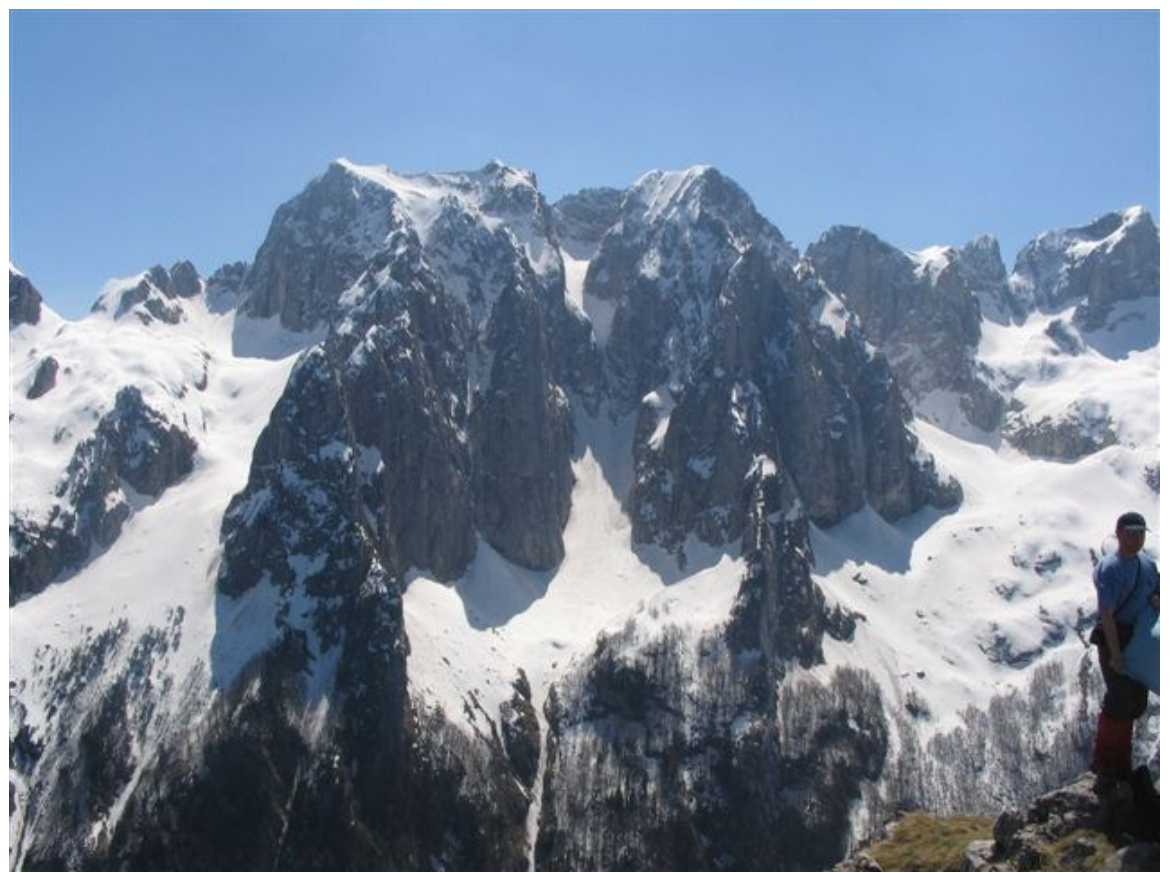

Figure 1. National Park - The nature the rarely seen Available from: http://www.plav.montenegro.travel (03.10 2014). 


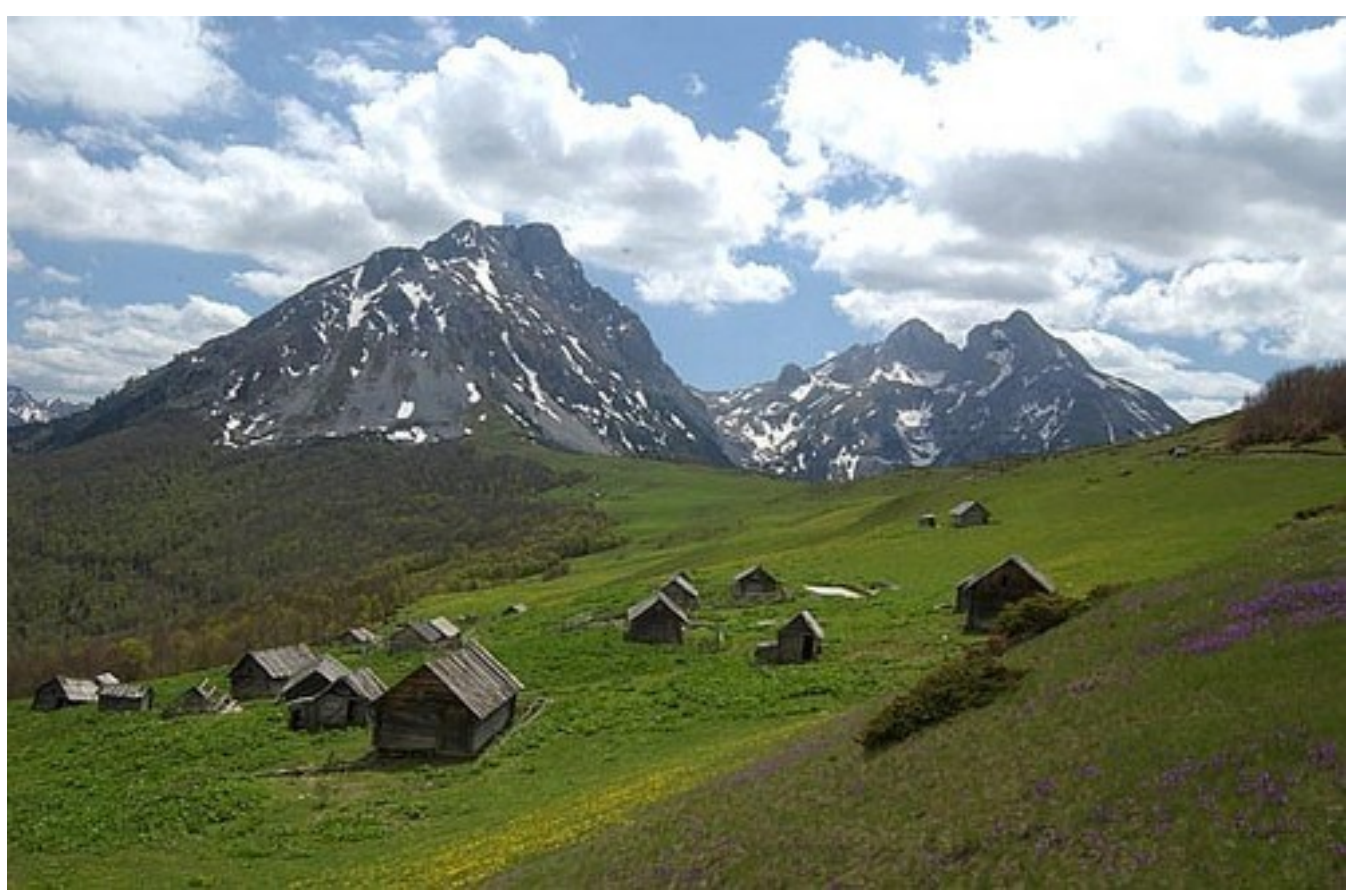

Figure 2. Komovi - Unique Dinaric mountain pearl Available from: http://www.summitpost.org(04.10 2014).

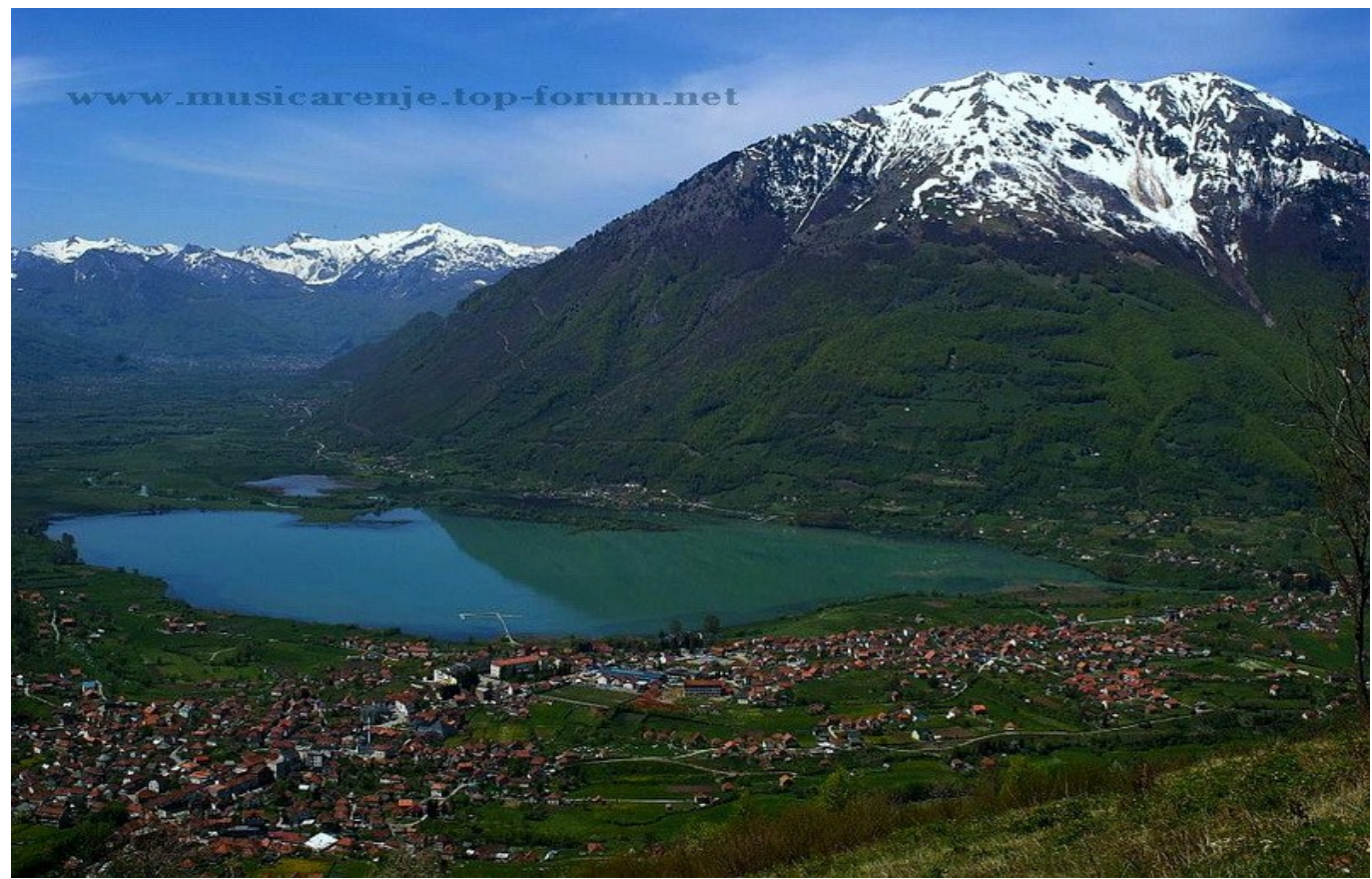

Figure 3. Plavsko Lake - the largest and most beautiful glacial lake in the Balkans Available from: http://www.plav.montenegro.travel (05.10 2014). 


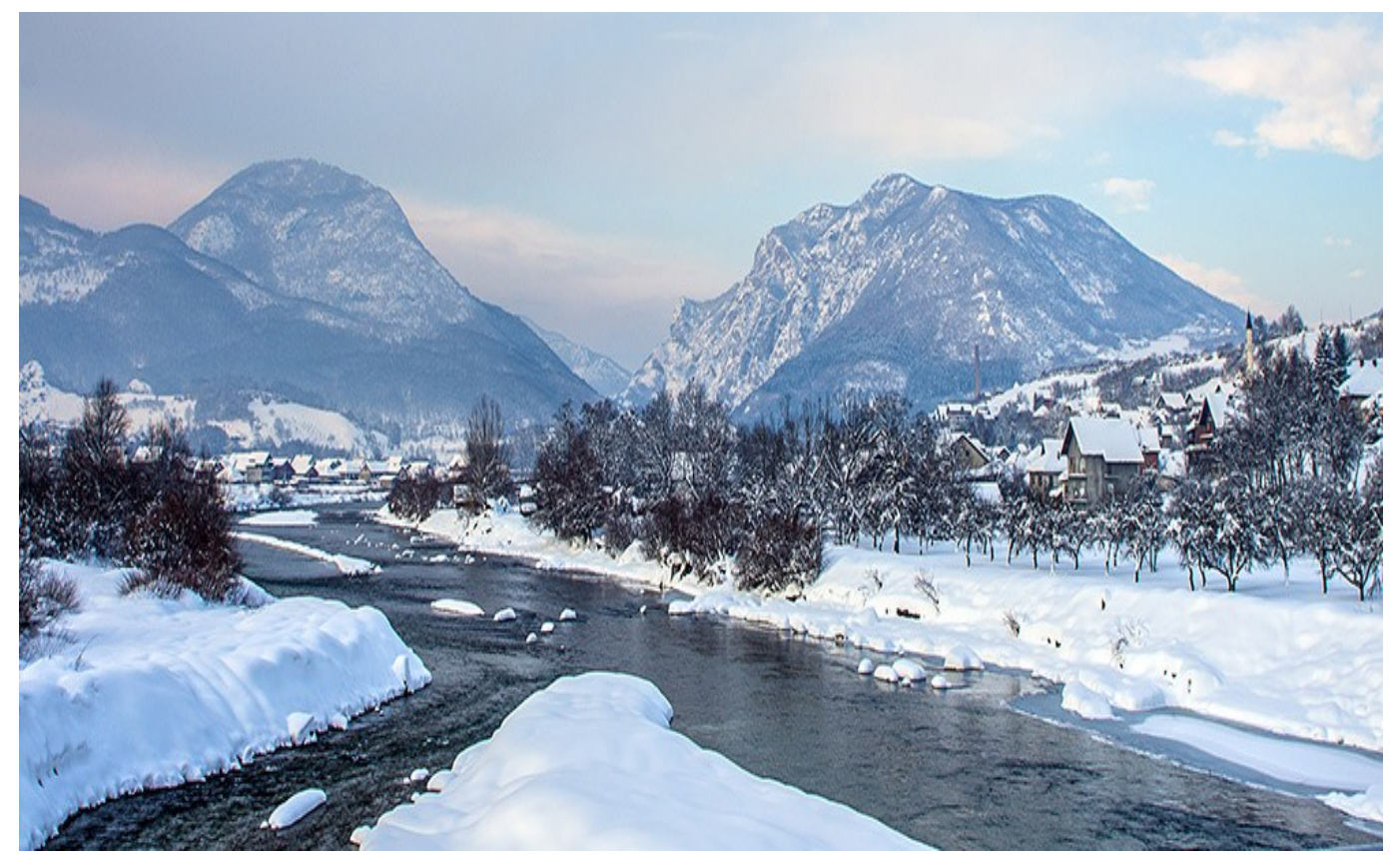

Figure 4. River Lim - magnificent winter Idyll

Available from: http://www.poslovnivodic.com (06.10 2014).

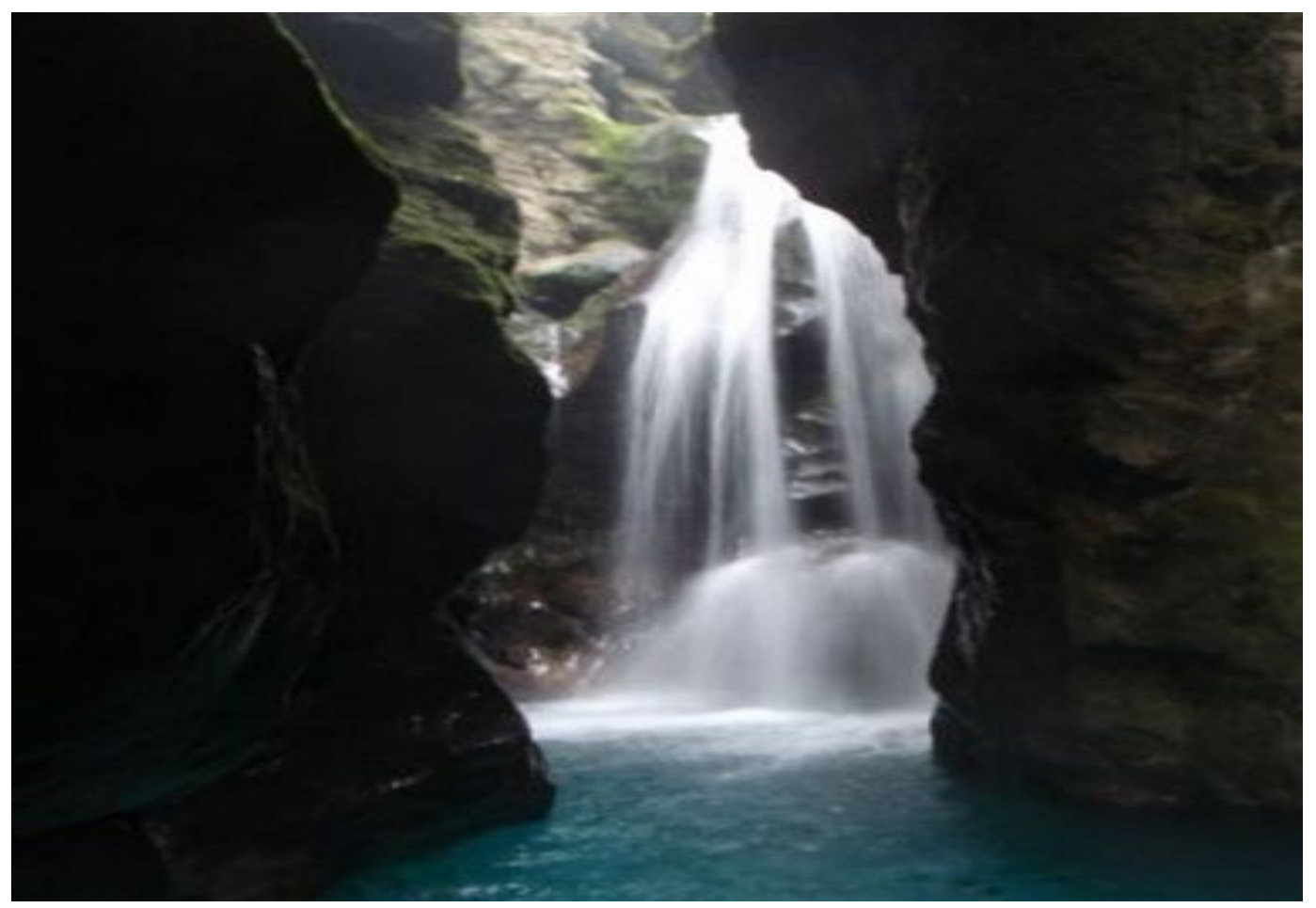

Figure 5. Canyon Grlje - discover the nature of Montenegro in the right way Available from: http://meetmontenegro.me (07.10 2014). 
Government of Montenegro the emphasized that education and awareness is one of are the priorities in the environmental sector. National the Parliament of Montenegro voted down the legislation in the field of environmental protection and their adoption at the institutional level are partly established rules of behavior of individuals and organizations in order to protect the environment. However, despite the application the law must be implemented and sustained programs of environmental education at all levels and encourage people to engage in activities aimed at protecting the environment.

\section{References}

[1] G. Rajović, J. Bulatović, International Letters of Natural Sciences 6 (2014) 57-68.

[2] G. Rajović, J. Bulatović, International Letters of Natural Sciences 14 (2014) 59-68.

[3] D. Ilić, M. Marković, Introduction to Ecological Education, Vranje, Aurora, 2010.

[4] M. Kundačina, Factors contributing to environmental education and education, Faculty of Education, Užice, 2006.

[5] L. Pušić, A. Pajvančić-Cizelj, Sociologija 54(1) (2012) 153-168.

[6] G. Rajović, Istraživanje i razvoj 13(1-2) (2007) 61-66.

[7] G. Rajović, Istraživanje i razvoj 14(28-29) (2008) 193-196.

[8] G. Rajović, Gorske staze 48 (2007) 10-11.

[9] G. Rajović, Gorske staze 49 (2007) 10-12.

[10] G. Rajović, Gorske staze 50 (2007) 9-13.

[11] A. Pinsonneault, L.K. Kraemer, Survey research methodology in management information systems: an assessment (2003), Available from: http://escholarship.org (15. 09 2014).

[12] J. Vallée, M. Souris, F. Fournet, A. Bochaton, V. Mobillion, K. Peyronnie, G. Salem, Emerging themes in epidemiology 4(1) (2007) 6.

[13] R.J. Evans, A. Mathur, Internet Research 15(2) (2005) 195-219.

[14] K. Kelley, B. Clark, V. Brown, J. Sitzia, International Journal for Quality in Health Care 15(3) (2003) 261-266.

[15] R. Tourangeau, Annu. Rev. Psychol. 55 (2004) 775-801.

[16] J.K. Jansen, K.G, Corley, J.B. Jansen, E-survey methodology, Handbook of research on electronic surveys and measurements (2007) 416-425.

[17] S. Starr, Journal of the Medical Library Association: JMLA 100(1) (2012) 1.

[18] D.R. Fricker, M. Schonlau, Field Methods 14(4) (2002) 347-367.

[19] R.L. Ramos, S. Goihman, Revista de Saúde Pública 23(6) (1989) 478-492.

[20] P. Collier, Cartography and Geographic Information Science 29(3) (2002) 155-174.

[21] C.J. Duque, R. Ramos, J. Suriñach, International Regional Science Review 30(3) (2007) $195-220$. 
[22] S. Abosedra, A. Dah, S. Ghosh, Applied Energy 86(4) (2009) 429-432.

[23] Lj. Rajšić, Ekonomika 48(1-3) (2002) 56-63.

[24] M. Andevski, Uvod u ekološko obrazovanje, Filozofski fakultet, Novi Sad,1997.

[25] I. Stamenković, A. Stamenković, Proceedings of the Department of Geography, Tourism and Hospitality 36 (2007) 123-136.

[26] A.M. Tarrant, K.H. Cordell, Environment and behavior 29(5) (1997) 618-637.

[27] B.D. Akinola, G.C. Ekpo, I.O. Haruno, Continental Journal of Environmental Sciences 6(3) (2012).

[28] C.B. Sarker, K.S. Sarker, S.M. Islam, S. Sharmin, Journal of Environmental Science and Natural Resources 5(2) (2013) 239-244.

[29] A. Franzen, Social science quarterly 84(2) (2003) 297-308.

[30] P. Huang, X. Zhang, X. Deng, Journal of Cleaner Production 14(18) (2006) 1635-1643.

[31] Q. Liu, M.H. Li, L.X. Zuo, F.F. Zhang, L. Wang, Journal of Cleaner Production 17(2) (2009) 265-270.

[32] Society of Young Researchers Bor, LEAP - Local Environmental Action Plan (2003), Available from: http://mibor.rs (28. 09 2014).

[33] G. Rajović, J. Bulatović, Ecologica 15(51) (2008) 45-52.

[34] J. Bulatović, G. Rajović, Zaštita prirode 61(2) (2011) 111-128.

[35] J. Bulatović, G. Rajović, International Journal of Advances in Management and Economics 2(1) (2013) 20-27.

[36] G. Rajović, J. Bulatović, International Letters of Social and Humanistic Sciences 1(2) (2015) 98-109.

[37] G. Rajović, J. Bulatović, Book of Abstracts, In International Conference" Globalization and the Environment", ,Ecologica "Scientific Society for Environmental Protection of Serbia, Belgrade, April 22-24 (2009).

[38] M. Knežević, Prokletije sačuvati za buduće generacije (2009), Available from: http:// www.pdpobeda.rs (29.09 2014).

[39] M. Pjević, Banjička forest, a treasure in the center of Belgrade (2002), Available from: http://www.treasurekeepers.rs (30.09 2014).

[40] Municipality Berane (2014), General data, Available from: http://www.berane.me (01.10 2014).

[41] J. Pretty, C. Angus, M. Bain, J. Barton, V. Gladwell, R. Hine, ..., M. Sellens, Nature, childhood, health and life pathways, Occasional Paper, 2, Interdisciplinary Centre for Environment and Society, University of Essex, UK, 2009.

[42] N. England, Childhood and Nature: a survey on changing relationships with nature across generations, Cambridge shire: Natural England, 2009. 
43] A. Akers, J. Barton, R. Cossey, P. Gainsford, M. Griffin, D. Micklewright, Environmental science \& technology 46(16) (2012) 8661-8666.

[44] Bureau for Culture of Vojvođanskih Slovaks (2014), Cultural Heritage, Available from: http://www.slovackizavod.org.rs (02.10 2014).

[45] Institute for Nature Protection of Serbia (2014), Report of the final event of the project "Environment in the youth policy in Serbia", Available from: http://www.zzps.rs (03.10 2014). 